Original paper

\title{
An Examination of the Self-Evaluations Over Time of 3.11 Tsunami Survivors Regarding Their Post-Disaster Recovery
}

\author{
Lee Young-Jun ${ }^{*}$ and Shinichi Hanada ${ }^{2}$
}

Received: 05/03/2020/ Accepted: 03/08/2020 / Published online: 27/08/2020

\begin{abstract}
In this study, the factors that affected the sense of recovery of the victims of the Great East Japan Earthquake were analyzed from both short-term and long-term perspectives. We used the results of questionnaire surveys conducted in 2013 and 2017 amongst residents of Noda Village, Iwate Prefecture, to determine the factors that affected the sense of recovery of their personal lives as well as their sense of the recovery of the village itself. We also examined how differences in the choice of temporary housing affected their sense of recovery. Utilizing decision tree analysis, we clarified differences in the key factors that impacted their short-term and long-term perspectives as well as the sense of their own recovery and their sense of the village's recovery. Because the introduction of publicly-funded rental housing deviated from the temporary housing networks available in previous disasters, there remains the possibility that although the short-term sense of recovery of those in publicly-funded temporary housing was relatively low, it seemed to increase over the long-term.
\end{abstract}

Key words: Great East Japan Earthquake, Sense of recovery, Publicly funded rental housing, Location-specific capital, Human networks, Disaster-recovery policies

\section{INTRODUCTION}

This study analyzes the factors affecting the sense of recovery, from both short-term and long-term perspectives, of those who survived the Great East Japan Earthquake. Specifically, we use the results of questionnaire surveys, conducted in 2013 and 2017, of the residents of Noda Village, located on the coast of Iwate Prefecture, to examine and identify the factors that

\footnotetext{
${ }^{1}$ Professor, Faculty of Humanities and Social Science, Hirosaki University, yjlee@ hirosaki-u.ac.jp

* Corresponding author

${ }^{2}$ Lecturer, Faculty of Humanities and Social Science, Hirosaki University
} 
have affected their sense of personal recovery as well as their sense of the recovery of the village itself.

The Great East Japan Earthquake was a complex disaster that consisted of an earthquake, a tsunami, and a nuclear accident. The earthquake and tsunami were the largest catastrophes in recorded Japanese history, with the disaster extending $500 \mathrm{~km}$ from north to south. Recovery from such a calamitous combination of disasters has understandably taken a long time.

According to "Changes in evacuation shelters following the Great East Japan Earthquake, the Great Hanshin-Awaji Earthquake, and the Chūetsu Earthquake," a report issued by the Reconstruction Agency and based on materials from the National Police Agency, Niigata Prefecture and Hyogo Prefecture, there were 307,022 evacuees recorded one week after the Great Hanshin-Awaji Earthquake, 76,615 after the Chūetsu Earthquake, and 386,739 after the Great East Japan Earthquake ${ }^{3}$. These numbers speak to the sheer magnitude of the damage in human terms inflicted by the Great Hanshin-Awaji Earthquake and the Great East Japan Earthquake.

Looking at the situation three months after the disasters, all evacuees from the Chūetsu Earthquake had been taken care of, whereas there were 50,466 evacuees remaining from the Great Hanshin-Awaji Earthquake and 88,361 from the Great East Japan Earthquake. One can clearly grasp the seriousness of the situation when this many people were forced to live in shelters or in other emergency living quarters three months following the disaster. Even after seven months, 21,899 people left homeless by the Great East Japan Earthquake were still living in evacuation centers, whereas 3,432 evacuees of the Great Hanshin-Awaji Earthquake remained in these centers. It can be seen that the restoration and reconstruction challenges left by the Great East Japan Earthquake were of a magnitude not seen in recent history.

The housing aspect of the recovery process in past disasters has followed a single path: initial emergency shelters, supplanted by the construction of temporary housing, followed by rebuilding. However, as pointed out by Kunitomo (2013), the Great East Japan Earthquake was a "rare disaster," with the number of temporary housing units that were needed rising to 30,000 , greatly exceeding the capacity to supply necessary emergency building materials. For this reason, the Ministry of Health, Labor and Welfare announced that it would recognize private temporary rental housing that victims could search for on their own, and that a post-disaster "publicly funded rental housing (minashi kasetsu jūtaku)" system would be introduced to provide rent subsidies. For this reason, it could be expected that the victims would have had a wider range of temporary housing options, and that there would have been a difference in their sense of recovery as a result of these expanded options.

Kuromiya et al. (2006) conducted a distinctive and notable study on how much time is required, what processes are involved and what social factors help bring about the recovery of the lives and livelihoods of people affected by natural disasters in Japan. Kuromiya et al. utilized Hyogo Prefecture panel data from 2001, 2003, and 2005 to grasp the extent to which

\footnotetext{
${ }^{3}$ Reconstruction Agency, "Changes in evacuation shelters and shelters" http://www.reconstruction.go.jp/topics/000185.html
} 
the victims' sense of recovery had grown over these years following the Great Hanshin-Awaji Earthquake. Their analysis showed that lives rooted in a community could be improved without repeated post-disaster relocations, and that active connections with other people in the community are an important factor in building up a sense of having recovered.

Using the same data as that utilized in this paper, Nagata (2018) found that in 2017, six years after the Great East Japan Earthquake, the sense of recovery had generally improved over that which had been revealed in a 2013 survey, two years following the disaster. In addition, it was revealed that one of the most relevant factors for improving the sense of recovery was whether the victim's relationship with people outside the village had increased or decreased after the disaster. Another important factor was whether or not the individual had been able to meet someone or others with whom he or she could open up to and talk with.

In many previous studies, the meaning of a social network, which includes family members and other relatives, neighbors and co-workers has been has been researched and clarified. Members of one's social network provide vital disaster assistance including the communication of warning messages and recovery information, the provision of supplies, search and rescue assistance, shelter during evacuation and rebuilding, social, emotional, and financial support as well as help with debris removal, rebuilding and repairs. Thus, social networks contribute to the ability of a person to respond and cope with extreme events (Eric and Faas (2017), Elliott et al.(2010) and Hawkins and Maurer (2010)). Meyer (2017) found that family members play a central role in disaster support networks.

However, these earlier studies did not examine the effects of differences in temporary housing on post-disaster senses of recovery, because, as Kunitomo (2013) revealed, the publicly funded rental housing system was introduced after the Great East Japan Earthquake. Researchers on disaster recovery before the Great East Japan Earthquake had therefore not been able to take this system into consideration when looking at temporary housing. However, when taking into account the likelihood of future disasters, one would think that vacant houses in a disaster area could be fully utilized as publicly funded rental housing, which leads one to conclude that a diversity of temporary housing options should be taken into consideration by policy makers.

This paper therefore focuses on the following two points for analysis. The first point is whether or not the factors that affect the sense of recovery change over time. The second is the question of which type of temporary post-disaster housing is chosen by or made available to victims and how this affects their sense of recovery.

The structure of this paper is as follows. In the following section, the sense of recovery is defined using utility functions, and the determinants of the sense of recovery are described. In the next three sections, we conduct an empirical analysis using the results of two questionnaires carried out by the authors amongst the affected people. Finally, Section 4 summarizes the results of the paper and describes the implications for recovery policy that are suggested by these results. 


\section{THEORETICAL FRAMEWORK}

Our analysis is based on the model of Lee, Nagata and Atsumi (2014). The reason we adopt their model is that it is a unique approach that uses location-specific capital to assess the human, social and economic impacts of a natural disaster. Our research, while referencing Lee, Nagata and Atsumi, focuses only on location-specific capital and the damage done to human networks. We assumed that the sense of recovery depends on the income and location specific capital before the disaster and the damage incurred as a result of the disaster.

Individuals' utility is assumed to be a function of their income (Y) and their stock of locationspecific capital (C). Location-specific capital is defined as human networks. An individual's utility function before and after a disaster as follows,

$$
\begin{aligned}
& U_{t=0}=U_{t=0}\left(Y_{t=0}, C_{t=0}\right) \\
& U_{t=1}=U_{t=1}\left((1-\alpha) Y_{t=0},(1-\beta) C_{t=0}\right)
\end{aligned}
$$

Where $U_{t=0}$ and $U_{t=1}$ denote the victim's satisfaction with life before the disaster and after the disaster, moreover, $\alpha$ and $\beta$ indicate the extent of the damage to income and locationspecific capital caused by the disaster.

The sense of recovery $(\mathrm{R})$ is calculated by the difference of an individual's sense of utility in the period before $\left(U_{t=0}\right)$ and $\operatorname{after}\left(U_{t=1}\right)$ the disaster. $\mathrm{R}$ is defined as follows.

$$
R \equiv U_{t=1} / U_{t=0}, \quad 0<R \leq 1
$$

The sense of recovery was determined by how life satisfaction after the disaster drew closer to life satisfaction before the disaster. If a survivor's current life satisfaction approached that of his or her life before the earthquake, the sense of recovery was close to 1 ; if satisfaction after the disaster was lower than before, the sense of recovery approached 0 .

From equations (1) and (2), the sense of recovery is determined as follows:

$$
R=R\left(Y_{t=0}, C_{t=0}, \alpha, \beta\right)
$$

That is to say, the sense of recovery depends on income and location-specific capital before the disaster and the damage incurred as a result of the disaster. In the questionnaire, it was not possible to obtain any information about the respondents' sense of satisfaction with their life before the disaster. We instead questioned them about their post-disaster sense of recovery. In 
the paper, we used the sense of recovery score for the proxy variable of $\mathrm{R}$, the comparison of the changes in the respondents' perceived sense of recovery before and after the disaster.

Several comparative statistical results emerge straightaway from the model. First, the sense of recovery decreases with the extent of damage to income caused by the disaster. Second, the sense of recovery also decreases when the damage done to location-specific capital increases. Third, the effects of income and the initial holdings of location-specific capital on the sense of recovery cannot be determined apart from one another.

\section{EMPIRICAL ANALYSES}

\subsection{DATA}

Our data were derived from the questionnaire surveys conducted by the authors in the village of Noda, located on the northern Sanriku Coast of Iwate Prefecture, in 2013 and 2017. Noda is a good example of a stricken coastal area. The population of Noda, according to the 2010 census, was 4,800 when the disaster occurred. A tsunami, 37.2 metres high, hit the centre of the village, killing 37 persons and obliterating or badly damaging 810 buildings and houses ${ }^{4}$. The most extensive damage was to the village centre and to basic industries such as fishing and agriculture.

The authors have been conducting disaster volunteer activities in Noda Village since the disaster struck in March 2011. Educational organizations, including Hirosaki University, Kyoto University, Osaka University, and the Hachinohe Institute of Technology, together with the Japan Disaster Relief Volunteer Network formed an organizational network called Team Kita-Rias and established an office in the affected area. The team engaged in immediate postdisaster activities such as sludge removal, food preparation, visits to and interviews at individual households. The team then moved on to help provide support for educational activities and to co-sponsor meetings related to reconstruction (Nagata (2012), Lee and Atsumi (2016)) As a result, Team Kita-Rias has been able to foster a relationship of trust with the villagers and obtain the cooperation of the Noda Village Office and other local bodies. This enabled the authors to conduct their "questionnaire survey on the lives and work of Noda villagers " in 2013 and again in 2017.

For the 2013 questionnaire survey, 2853 men and women between the ages of 18 and 69 who were listed in the village's Resident Registry as of February 2013 were included. On the other hand, the subjects of the 2017 survey were those who had graduated from Noda Junior High School, the only junior high school in the village. 1,276 individuals between the ages of 20 and 60 were surveyed. Of the 307 questionnaires that were received, 126 (41.0\%) were from

\footnotetext{
${ }^{4}$ For more information regarding the damage from the disaster, please refer to "Information on the Great East Japan Earthquake" on the Noda Village website. http://www.vill.noda.iwate.jp/bosai/378.html
} 
respondents who lived in the village at the time of the survey, whereas the rest resided outside the village $e^{5}$.

\subsection{Analytical Approach}

In this paper, the results of the 2013 and 2017 surveys are compared and the factors that have had short-term impacts and long-term impacts on the disaster victims' sense of recovery are discussed. First, the determinants of their sense of recovery were analyzed using decision tree analysis. Next, we analyzed the effects of initial shelter selection on the sense of recovery utilizing an ordered logit model.

Decision tree analysis is a data mining method based on machine learning and is used to determine the independent variables that influence the classification of a set of independent variables and their order. This method is sometimes used to predict damage in the event of disaster (Haimes (2012), Kim (2018), Luu (2017)). The boundary values of those independent variables that can be divided into two groups that form the greatest dependent variable differential are located and established as independent variables. Next, the boundary values of those independent variables that can be divided into two groups amongst the previously separated groups that form the greatest differential are located and established as independent variables. By repeating this until the difference falls within a certain range or until the difference reaches an established depth, it becomes possible to ascertain the influence of the independent variables on the dependent variables as well as their order.

In the case of this study, the sense of recovery is the dependent variable, and when the respondents are divided into two groups, the variable that maximizes the difference in the sense of recovery will be searched for. By analyzing common items in the 2013 and 2017 surveys as candidates for independent variables, it is possible to identify important factors in the sense of recovery, short-term important factors, and long-term important factors regardless of time. In this study, we use the CART (Classification and Regression Tree) Algorithm. This algorithm calculates the diversity of the dependent variable which was divided into two groups by the independent variables, and it chooses the level as well as the independent variable with the largest diversity. We use the Gini coefficient as the criteria for diversity, and stopped the algorithm when the number of observations in the group dropped to 20 or less.

There were two main reasons for using decision tree analysis in this study. First, since the sample size in the 2017 survey was particularly small, it would have been difficult to determine in advance those factors that would influence the sense of recovery. When doing regression analysis, it is necessary to establish in advance the independent variables that are to be used. However, the factors that affect the sense of recovery are not always obvious, so when the variables are selected it is possible that there may be a certain amount of arbitrariness involved.

\footnotetext{
${ }^{5}$ Because of the survey method, the dataset in 2017 included residents who had moved out of the Village. Since Noda Village was severely damaged, some of the residents had moved out of area over these 6 years. We included these villagers in our dataset taking this into consideration. For survey details see Lee et al. (2013, 2018).
} 
In addition, there were 34 items that were included in both the 2013 and 2017 surveys that were candidates to become independent variables. However, the sample size for 2017 was 111 , making it difficult to do an analysis using all the variables ${ }^{6}$. Although decision tree analysis also requires a certain sample size, it is not as affected by the number of independent variables as is regression analysis because it seeks out the two boundaries that can most clearly be separated.

Second, there is the possibility that decision trees, drawn as an outcome of decision tree analysis can be applied to future disasters. One of the areas where decision tree analysis is most often used is in marketing and in the forecasting of consumer behavior. For example, By forming a decision tree from past sales results and the like, the purchase probability and the preferences of each customer type are predicted and are used for target selection and other sales or marketing strategies. This idea can be applied to disaster recovery as well. In other words, if you were to create a decision tree for the sense of recovery from past disasters, it should be possible to predict, to some extent, the sense of recovery, according to the type of victim in future disasters. By doing so, care and recovery programs and approaches can be adopted that vary depending upon the sense of recovery of the individual victim.

Because decision trees are set up as hierarchies they can be broadly classified without detailed information, and because they may need less information than the results of regression analysis results, they were utilized for our analysis ${ }^{7}$. Although this is not a major reason, there are already many researches on the sense of recovery using regression analysis, and we are trying to increase our understanding by analyzing it from a different perspective.

The order logit model is a method for analyzing the influence of discrete sequenced items on the selection probability of each individual item at each step. In ordinary regression analysis, explanatory variables are continuous, but in questionnaires that use the five-step method, they cannot be used because the answers are ordinal scales. The ordinal logit model is a method for performing regression analysis on a discrete ordinal scale. Since the sense of recovery, which is a dependent variable in this study, is an ordinal scale based on the 4-step method, the analysis was performed using an ordinal logit model. The interpretation of the analysis results is basically the same as in ordinary regression analysis ${ }^{8}$.

\footnotetext{
${ }^{6}$ There was only one respondent residing in temporary housing in the 2017 survey, which could not be identified as a personal effect. In the 2017 survey, about $80 \%$ of the respondents answered that their recovery was 1 , and there were few variations. This suggests that the recovery was progressing smoothly at the individual's life level, which is not a bad thing, but it still poses a problem for analysis.

${ }^{7}$ Note that since decision tree analysis is a method of searching for a boundary to divide groups, it would be difficult for a variable having a small number of corresponding answers to become a boundary. For this reason, for those items where the number of affected persons in Great East Japan Earthquake or in Noda Village was small, it is difficult to evaluate that these items are important or not. In order to apply this to disasters in general, it will be necessary to conduct similar analyses of other disasters and to deepen our knowledge of possible postdisaster programs.

${ }^{8}$ The coefficient calculated by the ordinal logit model is strictly an effect on the latent variable that affects the selection probability, and does not directly indicate the range that increases the selection probability. However, the interpretation of the sign and the comparison of the magnitude of the coefficients can be performed by the same interpretation as in ordinary regression analysis.
} 
The reason for using the ordinal logit model to analyze the effects of housing is because it makes it possible to evaluate the impact of housing comparatively, while controlling other factors. In the case of decision tree analysis, in order to determine the boundaries at the time of the division into two groups, all of the variables are not necessarily used for the evaluations. Nor can comparable quantitative indicators be obtained. In regression analysis, after removing the influence of other established independent variables, the magnitude of the influence on the independent variables can be measured. At this time, if the scales of the independent variables are the same, the magnitude of the influence can be analyzed by directly comparing the magnitudes of the coefficients. In this study, we used the ordinal logit model because the occupied houses were used as dummy variables and therefore had the same scale, which allowed for a direct comparison of the estimated results.

Table 1-1. Descriptive statistics of survey results

\begin{tabular}{|c|c|c|c|}
\hline Variables & 2013 & 2017 & note \\
\hline Personal Recovery & 1.97 & 1.38 & 4 steps (Almost full recovery (1) to Absolutely no recovery(4)) \\
\hline Village Recovery & 2.97 & 2.30 & 4 steps (Almost full recovery (1) to Absolutely no recovery(4)) \\
\hline \multicolumn{4}{|l|}{ Evacuation housing } \\
\hline Same house & $74.5 \%$ & $79.3 \%$ & \\
\hline Different house & $4.0 \%$ & $9.9 \%$ & \\
\hline Temporary housing & $11.9 \%$ & $0.9 \%$ & \\
\hline Public-funded rental housing & $4.0 \%$ & $1.8 \%$ & \\
\hline Others & $5.6 \%$ & $4.5 \%$ & \\
\hline Damage to housing & 2.14 & 1.68 & 5 steps (No damage (1) to Completely destroyed (5)) \\
\hline Increase/Decrease of personal relationships & & & 3 steps (Increase (1) to Decrease (3)) \\
\hline Immidiate family and other relatives & 1.98 & 1.92 & \\
\hline Local human network & 2.08 & 2.03 & \\
\hline Friends in the workplace & 2.05 & 1.90 & \\
\hline Person outside the village & 2.01 & 1.84 & \\
\hline Within walking distance (before the disaster) & & & Number \\
\hline Immidiate family and other relatives & 8.89 & 6.60 & SD 8.55, 0 to 50 (2013), SD 6.73, 0 to 40 (2017) \\
\hline Local human network & 9.33 & 4.51 & SD $15.2,0$ to 200 (2013), SD 6.02, 0 to 30 (2017) \\
\hline Friends in the workplace & 4.60 & 4.46 & SD 9.55, 0 to 100 (2013), SD 15.4, 0 to 150 (2017) \\
\hline Within walking distance (after the disaster) & & & Number \\
\hline Immidiate family and other relatives & 8.98 & 6.55 & SD $18.4,0$ to 300 (2013), SD 6.56, 0 to 40 (2017) \\
\hline Local human network & 9.17 & 4.69 & SD 22.1, 0 to 300 (2013), SD 6.01, 0 to 30 (2017) \\
\hline Friends in the workplace & 4.24 & 5.18 & SD 9.39, 0 to 100 (2013), SD 15.8, 0 to 150 (2017) \\
\hline Change in numbers of persons before and after disaster & & & $\begin{array}{l}\text { Subtracting number of personzs } \\
\text { before the disaster from after the disaster }\end{array}$ \\
\hline Immidiate family and other relatives & 0.09 & -0.05 & SD $14.9,-30$ to $250(2013)$, SD $3.63,-33$ to 10 (2017) \\
\hline Local human network & -0.17 & 0.18 & SD $15.3,-35$ to 250 (2013), SD $1.48,-5$ to 3 (2017) \\
\hline Friends in the workplace & -0.36 & 0.71 & SD 3.07, -29 to 17 (2013), SD 3.57, -9 to 20 (2017) \\
\hline Give advice & & & 3 steps (Often (1) to Never (3)) \\
\hline Immidiate family and other relatives & 1.91 & 2.13 & \\
\hline Other Villagers & 2.25 & 2.56 & \\
\hline Gender & 1.47 & 1.52 & Male (1), Female (2) \\
\hline Age & 46.5 & 36.7 & \\
\hline Eldest child & 1.37 & 1.47 & Eldest (1), Not the eldest (2) \\
\hline Educational level & 3.33 & 3.05 & Primary school (1) to University/Graduate school (6) \\
\hline Marriage status & 1.67 & 1.86 & Married (1), Separated/Widowed (2), Single (3) \\
\hline Children & 1.57 & 1.47 & Yes (1), No (2) \\
\hline Household size & & & One person (1) to 5 person or more (5) \\
\hline Before the disaster & 3.49 & 3.50 & \\
\hline After the disaster & 3.36 & 3.10 & \\
\hline Change & -0.13 & -0.40 & $\begin{array}{l}\text { Subtracting number of personzs } \\
\text { before the disaster from after the disaster }\end{array}$ \\
\hline Household income & 4.73 & 5.41 & 9 steps (Zero (1) to $\backslash 10,000,000$ or more(9)) \\
\hline Change brought on by the disaster & & & 3 steps (Increased (1) to Dicreased (3) \\
\hline Household income & 2.31 & 1.90 & \\
\hline Household expenses & 1.56 & 1.45 & \\
\hline Household savings & 2.51 & 2.16 & \\
\hline Number of observations & 302 & 111 & \\
\hline
\end{tabular}


Table 1-2. Distributions of answers

\begin{tabular}{|c|c|c|c|c|c|c|c|}
\hline Variables & Year & 1 & 2 & 3 & 4 & 5 & Obs. \\
\hline Personal Recovery & 2013 & $49 \%$ & $13 \%$ & $30 \%$ & $8 \%$ & - & 302 \\
\hline (Almost full recovery (1) to Absolutely no recovery(4)) & 2017 & $79 \%$ & $8 \%$ & $8 \%$ & $5 \%$ & - & 111 \\
\hline Village Recovery & 2013 & $2 \%$ & $8 \%$ & $79 \%$ & $10 \%$ & - & 302 \\
\hline (Almost full recovery (1) to Absolutely no recovery(4)) & 2017 & $17 \%$ & $41 \%$ & $38 \%$ & $5 \%$ & - & 111 \\
\hline Damage to housing & 2013 & $64 \%$ & $6 \%$ & $1 \%$ & $9 \%$ & $19 \%$ & 302 \\
\hline (No damage (1) to Completely destroyed (5)) & 2017 & $78 \%$ & $6 \%$ & $3 \%$ & $1 \%$ & $12 \%$ & 111 \\
\hline \multicolumn{8}{|l|}{ Increase/Decrease of personal relationships } \\
\hline Immidiate family and other relatives & 2013 & $12 \%$ & $78 \%$ & $10 \%$ & - & - & 302 \\
\hline (Increase (1) to Decrease (3)) & 2017 & $16 \%$ & $76 \%$ & $8 \%$ & - & - & 111 \\
\hline Local human network & 2013 & $11 \%$ & $70 \%$ & $19 \%$ & - & - & 302 \\
\hline (Increase (1) to Decrease (3)) & 2017 & $11 \%$ & $76 \%$ & $14 \%$ & - & - & 111 \\
\hline Friends in the workplace & 2013 & $12 \%$ & $72 \%$ & $17 \%$ & - & - & 302 \\
\hline (Increase (1) to Decrease (3)) & 2017 & $14 \%$ & $81 \%$ & $5 \%$ & - & - & 111 \\
\hline Person outside the village & 2013 & $15 \%$ & $70 \%$ & $16 \%$ & - & - & 302 \\
\hline (Increase (1) to Decrease (3)) & 2017 & $21 \%$ & $75 \%$ & $5 \%$ & - & - & 111 \\
\hline
\end{tabular}

In this study, we analyzed only those items that appeared in both the 2013 and 2017 surveys. These are summarized in Table 1-1 and Table 1-2. In the decision tree analysis, if there was no answer provided for any of these items, they were excluded from the sample. As a result, the number of observations was 302 for the 2013 survey and 111 for the 2017 survey.

We tested the differences in demographics from before the disaster and between the two samples9. Because "Age" was significantly lower in 2017 there were more respondents with "Single" marriage status in 2017. We included respondents outside of the village in 2017, so the ratio of "Not the eldest child" increased in 2017. Other demographics showed no not significant difference.

\subsection{Analysis results}

Before going into a detailed analysis, we will first take a look at the changes in the 2013 and 2017 responses. First of all, the numerical values for the two entries related to the sense of recovery were smaller in 2017 than in 2013, indicating that recovery was progressing. Taking into consideration that recovery and reconstruction progress over time, this is a natural outcome (Nagata (2018).

As for evacuation housing, around $16 \%$ of respondents in the 2013 survey were living in temporary or publicly funded rental housing. But that figure had fallen to about $3 \%$ by the time of the 2017 survey. A possible reason for this change is that the proportion of persons residing in Noda who responded to the 2017 survey was high. It can also to be assumed that the homes of those who were moved into temporary or publicly funded rental housing had been severely damaged by the earthquake or the tsunami. The 2013 survey was conducted around 2 years after the disaster, so it is possible that the residents continued to live in temporary housing.

\footnotetext{
${ }^{9}$ Some demographics were indicated after the disaster. We did not test these variables because they possibly included the impact of the passage of time.
} 


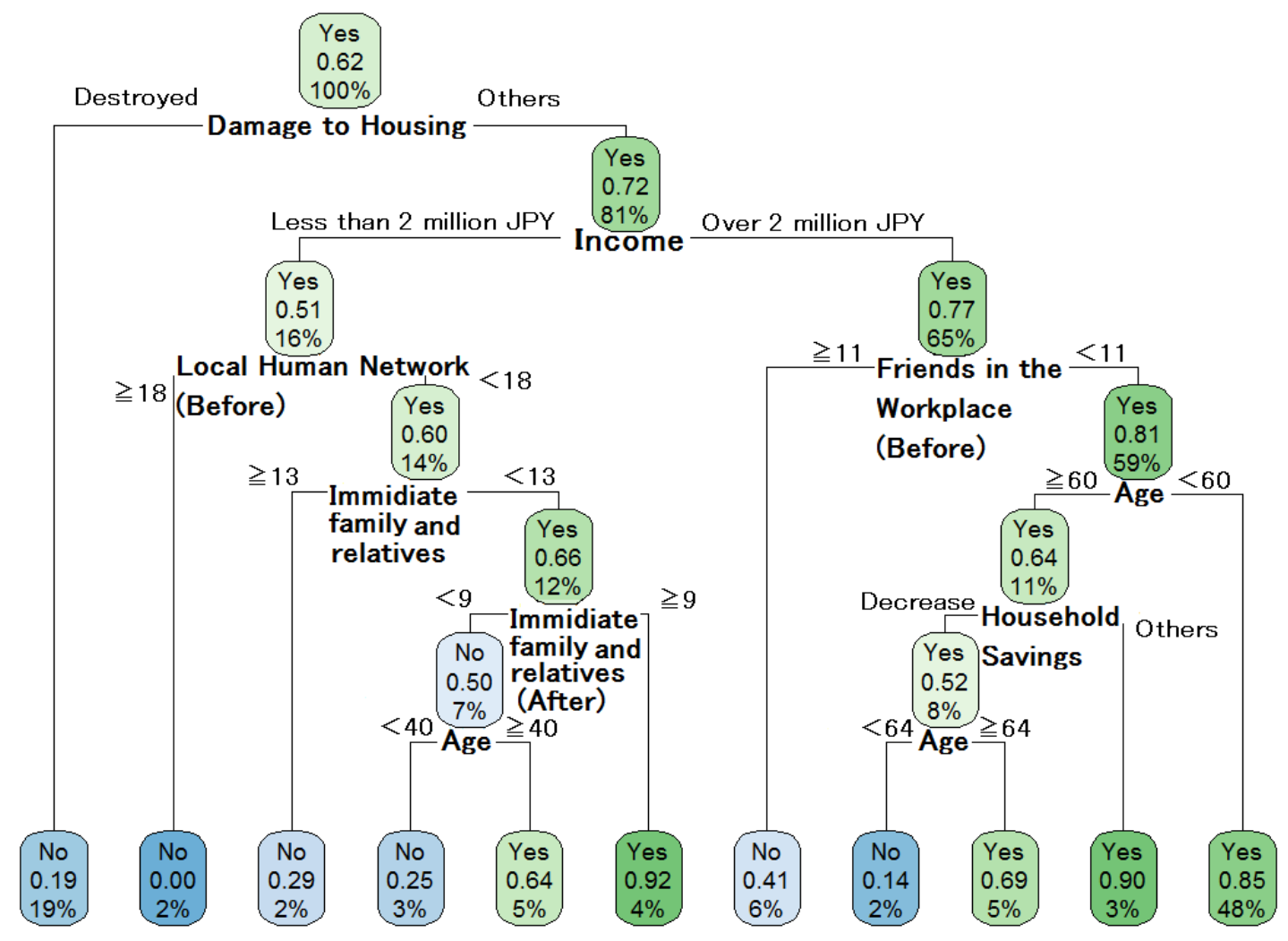

(2013)

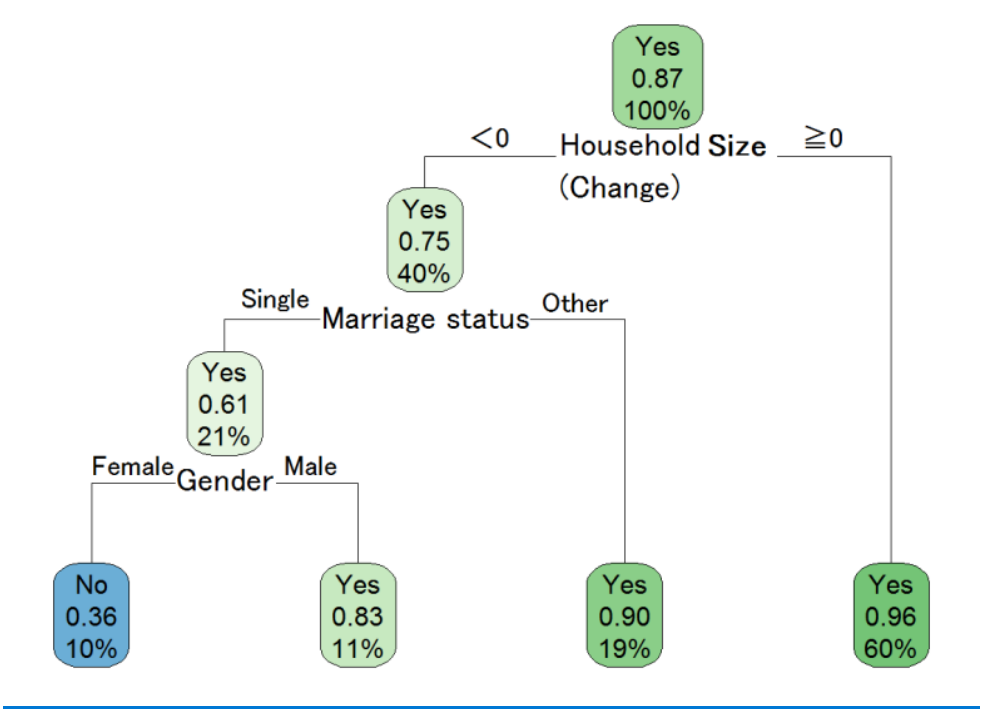

(2017)

Figure 1. Decision tree for the personal sense of recovery ${ }^{10}$

\footnotetext{
${ }^{10}$ The top of each nodal square indicates the dominant response for that group. The middle numbers indicate the percentage of those expressing "non-recovery" within the group. The numbers at the bottom indicate the ratio of the group to the entire sample. Below the node are the variables and their values that serve as boundaries; on the left are the groups that meet the conditions for a boundary; on the right are those that do not.
} 
However, by the time of the 2017 survey, more than 5 years after the disaster, it is possible that most of the victims had moved on from their temporary living quarters.

Regarding the number of family members and others who resided within walking distance, in the 2017 survey the number of immediate family members or other relatives as well as the number of acquaintances had decreased, whereas the number of workplace friends had increased. This may indicate that post-disaster recovery and reconstruction was progressing and that a return to one's place of work had occurred.

In addition, the 2017 survey showed improved results for income, expenditures and savings when compared with their pre- and short-term post-disaster circumstances. This may be an indication that lives had improved due to the progress of reconstruction and recovery.

\subsubsection{Decision tree analysis results}

First, we analyzed how victims viewed their own sense of recovery. The dependent variable was a 4-step configuration and it was possible for analysis to be carried out employing a continuous variable or broken down into two divisions based on a certain reference points. Although analysis was carried out utilizing both approaches, no significant differences emerged. Therefore, this paper describes only the results of the two-division approach ${ }^{11}$. As for the two divisions, answers 1 and 2 were categorized as "recovered" and 3 and 4 "not-yet recovered".

The left side of Fig. 1 shows the results for 2013 and the right side for those of 2017. Looking at the 2013 results, the sense of recovery was low if the victim's home had been completely destroyed. If household income was low and the number of the victim's acquaintances before the disaster had been large, the sense of recovery was also low. If household income was above a certain level and the number of workplace friends in which the victim was in contact after the disaster was large, the sense of recovery was high. Furthermore, if household income was low and the number of pre-disaster friends was high the sense of recovery was low. Next, looking at the 2017 results, the sense of recovery was high if the number of household members had not decreased. When the number of household members had dropped, the sense of recovery was high if they were married. Women who were not married tended to have a low sense of recovery.

Comparing the results of the 2013 and 2017 surveys, the impact of the damage to one's home, which was a significant factor in 2013, had lost its significance in 2017. On the other hand, being married or not, which had little effect in 2013 was of consequence in 2017. In both 2013 and 2017, changes in the number of households, changes in household income and savings, as well as changes in family composition and the changing economic environment were factors that showed an impact.

\footnotetext{
${ }^{11}$ Some of the conclusions reflect the results of analysis using continuous variables.
} 
Next, we analyzed the sense of recovery of Noda itself using a decision tree. The left side of Figure 2 shows the 2013 results; on the right are those for 2017. Only $10 \%$ of the responses had answer at or below option 2, so it was not possible to establish a group with a high sense of recovery. When comparing these results to the personal sense of recovery, changes in the entries for the number of family members and relatives, the number of local acquaintances, the number of friends in the workplace, and the number of households in the area showed common outcomes for both. On the other hand, entries such as changes in relationships with persons outside of the village, the number of children, and changes in income did not affect one's personal sense of recovery, but did affect their sense of the village's recovery.

The results of the 2017 survey indicated that post-disaster household size had an impact; if the number of members of a household was above a certain number, the sense of recovery tended to be high. If the number of household members after the disaster was small, but the number of post-disaster workplace friends was large, the sense of recovery was also high. In addition, even if the number of workplace friends was small, the sense of recovery was high if damage to one's house was minimal. If the damage to the home was above a certain level, the sense of recovery diminished as household size increased.

\subsubsection{Changes over time in factors affecting the sense of recovery}

Table 2 summarizes the results of the above analysis. The underlined elements are those that affect both the individual's sense of his or her own sense of recovery as well as that of the village. Also, (before) and (after) indicate the number of people before and after the disaster, respectively ${ }^{12}$.

First, in both the 2013 and 2017 surveys, the number of local workplace friends before the disaster and the number after the disaster as well as changes in household size affected both their own sense of recovery and their sense of village recovery. In 2013, both the sense of personal recovery and the sense of the village's recovery were affected by damage to homes, the number of immediate family members and other relatives who were in the area before and after the disaster, the number of friends who were nearby after the disaster and subsequent changes in the number of these friends, changes in family membership, consultations with villagers, and changes in household income due to the disaster. In 2017, none of these factors affected the sense of individual recovery or village recovery.

\footnotetext{
${ }^{12}$ It should be noted that decision tree analysis has a feature where, due to the nature of grouping, variables having a small number of relevant respondents are difficult to be adopted as boundaries. The results show the importance of variables for which a certain number of responses were received.
} 


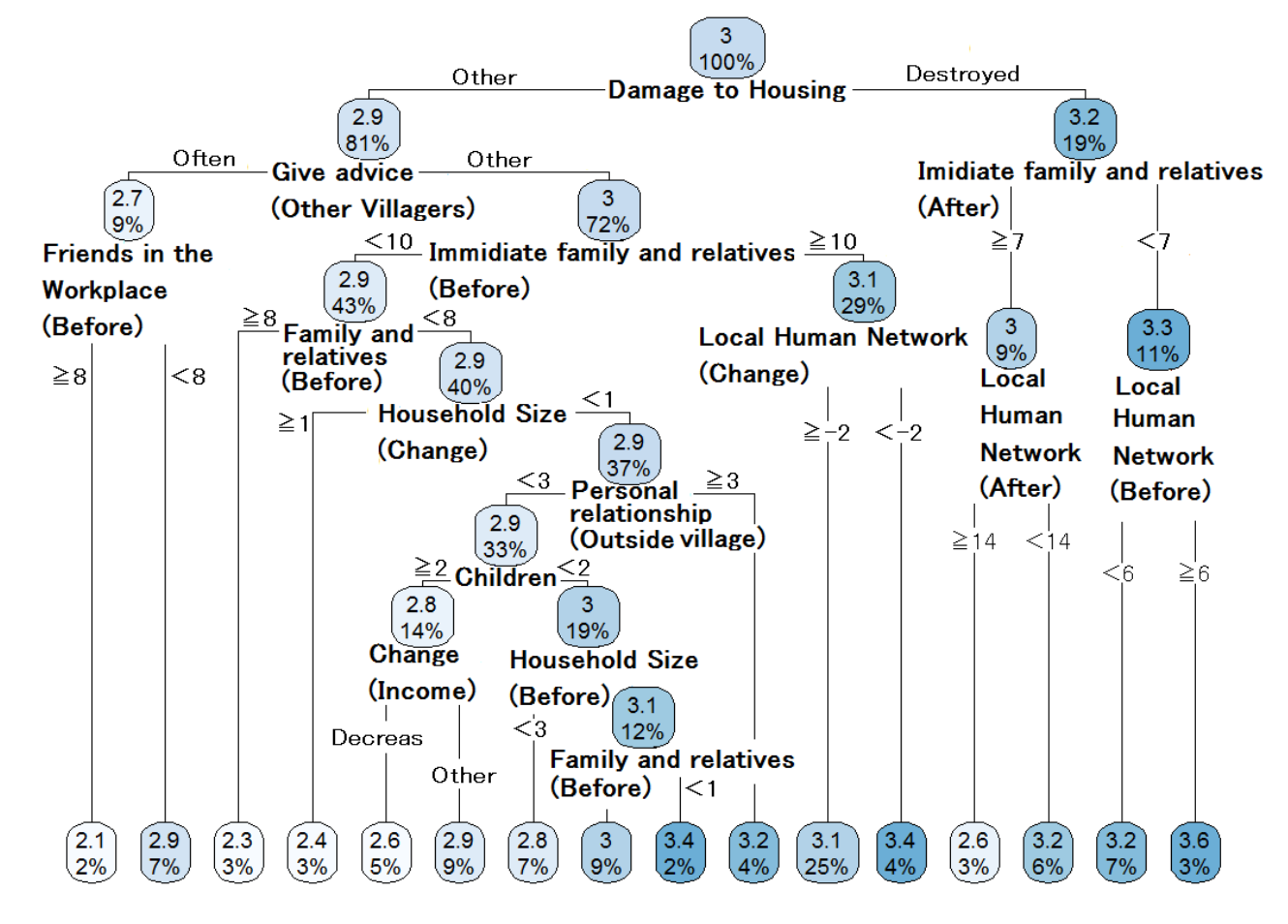

(2013)

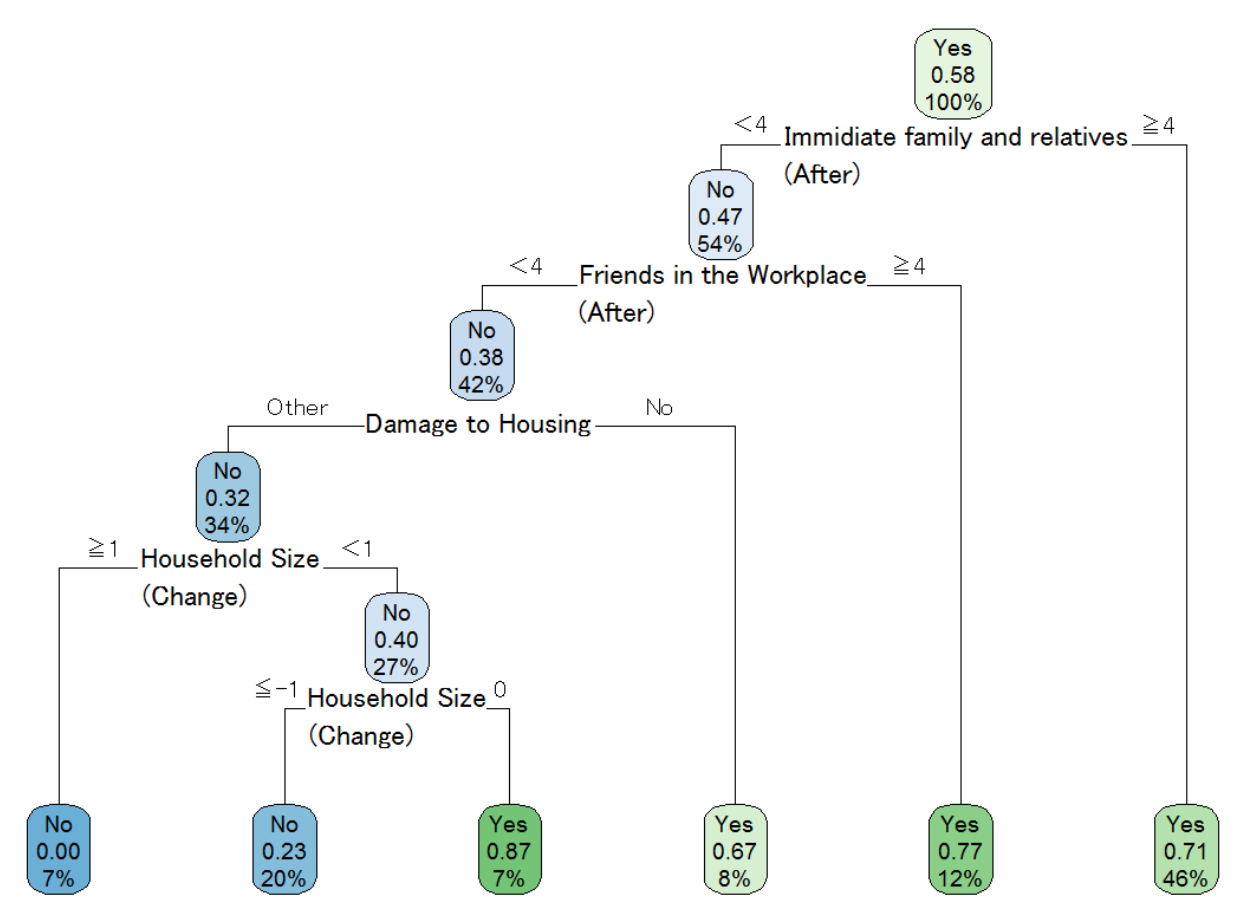

(2017)

Figure 2. Decision tree for the sense of recovery of the village 
Table 2 Key factors for sense of recovery ${ }^{13}$.

\begin{tabular}{|c|c|c|}
\hline & Influence on personal recovery & Influence on village recovery \\
\hline 2013 only & $\begin{array}{l}\text { Damage to housing, number of } \\
\text { family members and other relatives } \\
\text { (before) (after), number of local } \\
\text { friends (after), change in the } \\
\text { number of local friends, advice \& } \\
\text { counsel (villagers), age, changes } \\
\text { due to the disaster (household } \\
\text { income) }\end{array}$ & $\begin{array}{l}\text { Changes in relationships with } \\
\text { persons outside the village, number } \\
\text { of family members and other } \\
\text { relatives (before) (after), changes in } \\
\text { the number of friends in the } \\
\text { community, advice \& counsel } \\
\text { (villagers), children, number of } \\
\text { households (before) }\end{array}$ \\
\hline Both years & $\begin{array}{l}\text { Number of local friends (before), } \\
\text { number of friends at work (before) } \\
\text { (after), gender, changes in the } \\
\text { number of households, household } \\
\text { income, changes due to the disaster } \\
\text { (household savings) }\end{array}$ & $\begin{array}{l}\text { Damage to housing, number of } \\
\text { local friends (before) (after), } \\
\text { number of friends at work (after), } \\
\text { changes in the number of } \\
\text { households, changes due to the } \\
\text { disaster (household income) }\end{array}$ \\
\hline 2017 only & Marriage status & $\begin{array}{l}\text { Advice and counsel (immediate } \\
\text { family / relatives), age, firstborn } \\
\text { child, educational background, } \\
\text { number of households (after) }\end{array}$ \\
\hline
\end{tabular}

As for the sense of personal recovery, pre-disaster factors such as the number of workplace friends, gender and household income were factors in both the 2013 and 2017 surveys. In the 2013 survey, factors such as damage to homes, the number of friends in the area after the disaster, age and changes in income due to the disaster affected their sense of recovery, whereas in the 2017 survey they did not. On the other hand, in the 2017 survey, whether or not they were married influenced their sense of recovery.

Regarding the sense of recovery of the village, damage to homes, the number of friends in the area after the disaster, and changes in household income due to the disaster affected the sense of recovery in both the 2013 and 2017 surveys. On the other hand, factors such as changes in social relations outside the village, the number of children, and the number of households before the disaster affected the sense of village recovery in the 2013 survey, but did not in the 2017 survey. In the 2017 survey, having family members or other relatives available to offer

\footnotetext{
${ }^{13}$ In the section 3.3.1, we describes only the results of the two-division approach. We describe the decision tree which uses dependent variables as continuous. Because Table 2 reflects the results of both, some dependent variables are added.
} 
advice and counsel, age, being the firstborn or not, educational background, and the number of household members after the disaster had emerged as factors.

\subsubsection{Results of ordinal logit analysis}

Next, we analyzed the impact of the type of housing into which victims moved after the disaster and their sense of recovery using the ordered logit model. The dependent variables were the sense of personal recovery and the sense of village recovery. The independent variables were based on the results of the decision tree analysis described above. We used changes in the number of workplace friends, gender, household size, household income, and post-disaster changes (household savings).

For the sense of village recovery, we used the number of local friends and acquaintances before and after the disaster, the number of friends in the post-disaster workplace, changes in household size, the extent of damage to one's home, and other post-disaster changes (household income). In both analyses, the types of housing into which displaced persons lived or were placed after the disaster were divided into 9 categories and included as independent variables: one's own home (resided in before the disaster), one's own home (different from that resided in before the disaster), temporary housing, publicly-funded rental housing, plus five other categories.

The sense of personal recovery is set forth in Table $3^{14}$. The sense of recovery is the dependent variable; the smaller the number the higher the sense of recovery. This indicates that the variable with a negative estimated coefficient has the effect of increasing the sense of recovery, while a positive one has the effect of reducing the sense of recovery. In addition, the value assigned to the first living quarters in which the disaster victim lived was based on the victim's pre-disaster home. First, the coefficient of household income was negative and significant in both 2013 and 2017, indicating that the higher the household income, the higher the sense of recovery. In addition, the coefficient of change (household savings) after the disaster was positive and significant, indicating that an increase in savings increased the sense of recovery. Other variables were not statistically significant.

As for the type of housing into which the victim moved after the disaster, there was no significant difference between living in the home that one lived in prior to the disaster and other housing. However, in 2013, the coefficients were all positive, indicating that having a home in the same location led to the highest sense of recovery. In 2013 the coefficients were all positive, indicating that remaining in one's own pre-disaster home brought on a high sense of recovery, whereas in 2017 the coefficients were negative, suggesting the possibility that this choice had not enhanced their sense of recovery.

Moving on to a comparison of the size of the coefficients, in 2013, living in one's predisaster home>one's own home in a different location>temporary housing>publicly funded

\footnotetext{
${ }^{14}$ Only those independent variables that showed significant results, other than those relating to the home, were shown. In the calculations, all of the independent variables listed above were used.
} 
rental housing. In 2017, living in one's own home in a different location>publicly funded rental housing >one's pre-disaster home>temporary housing. In the short term, living in the house in which one was familiar seemed to have increased the sense of recovery, but in the long term this was not necessarily the case. In the short-term, publicly funded rental housing correlated with a low sense of recovery, although the results suggest that this was not necessarily so for the long-term sense of recovery. In the long-term this did not necessarily diminish the sense of recovery.

Table 3 - Results of the ordered logit analysis

\begin{tabular}{|c|c|c|c|c|}
\hline & \multicolumn{2}{|c|}{ Personal Recovery } & \multicolumn{2}{|c|}{ Village Recovery } \\
\hline & 2013 & 2017 & 2013 & 2017 \\
\hline \multirow[t]{3}{*}{ Household Income } & -0.24 & -0.45 & & \\
\hline & $(0.07]^{* * *}$ & $(0.15]^{* * *}$ & & \\
\hline & {$[-0.37,-0.11]$} & {$[-0.74,-0.15]$} & & \\
\hline Change by the disaster & 0.33 & 0.93 & & \\
\hline \multirow[t]{2}{*}{ (Household savings) } & $(0.19)^{*}$ & $(0.44)^{* *}$ & & \\
\hline & {$[-0.05,0.70]$} & {$[0.07,1.78]$} & & \\
\hline \multirow[t]{3}{*}{ Damage to housing } & & & 0.23 & 0.07 \\
\hline & & & $(0.09)^{* *}$ & $(0.16)$ \\
\hline & & & {$[0.05,0.41]$} & {$[-0.24,0.38]$} \\
\hline Household size & & & -0.58 & -0.26 \\
\hline \multirow[t]{2}{*}{ (Change) } & & & $(0.20)^{* * *}$ & $(0.12)^{* *}$ \\
\hline & & & {$[-0.97,-0.19]$} & {$[-0.46,-0.02]$} \\
\hline \multirow[t]{3}{*}{ Temporary housing } & 0.05 & 2.42 & -0.39 & 1.58 \\
\hline & $(0.34)$ & (1.58) & $(0.44)$ & (1.93) \\
\hline & {$[-0.61,0.71]$} & {$[-0.69,5.52]$} & {$[-1.25,0.47]$} & {$[-2.20,5.36]$} \\
\hline \multirow[t]{3}{*}{ Public funded rental housing } & 0.66 & -0.33 & -0.18 & -2.05 \\
\hline & $(0.57)$ & (1.27) & $(0.76)$ & $(1.06)^{*}$ \\
\hline & {$[-0.45,1.78]$} & {$[-2.81,2.15]$} & {$[-1.67,1.31]$} & {$[-4.13,0.03]$} \\
\hline \multirow[t]{3}{*}{ Different house } & 0.03 & -0.88 & 0.04 & -0.01 \\
\hline & $(0.58)$ & (1.16) & $(0.74)$ & $(0.06)$ \\
\hline & {$[-1.10,1.17]$} & {$[-3.15,1.39]$} & {$[-1.41,1.49]$} & {$[-0.13,0.11]$} \\
\hline \multirow[t]{3}{*}{ Others } & -0.13 & 0.68 & -0.38 & -1.48 \\
\hline & $(0.49)$ & (0.99) & $(0.64)$ & $(0.98)$ \\
\hline & {$[-1.09,0.82]$} & {$[-1.26,2.62]$} & {$[-1.63,0.87]$} & {$[-3.40,0.44]$} \\
\hline Log liklihood & -341 & -67 & -201 & -121 \\
\hline Number of Observations & 302 & 111 & 302 & 111 \\
\hline
\end{tabular}

Standard errors in parentheses

$* * *<<0.01, * * p<0.05, * p<0.1$

Next, looking at the results of the sense of village revival, the housing damage coefficient was positive and significant in 2013, indicating that the greater the damage to the house, the lower the sense of recovery. In 2017, however, this coefficient had lost its significance. Changes in household size were negative and significant in both years, indicating that a reduction in the size of a household contributed to a diminished sense of recovery of the village. Other coefficients were not significant.

Looking at the housing occupied after the disaster, in 2013, temporary housing>publicly funded rental housing >one's pre-disaster home>a home in another location. For 2017, publicly funded rental housing $>$ a home in another location $>$ one's pre-disaster home $>$ temporary housing. 
In 2013 and 2017, the order of the pre-disaster home and a home in a different location were reversed, with publicly funded rental housing having the highest ranking in 2017.

The above results show that publicly funded rental housing tended to reduce the personal sense of recovery in the short-term compared to living in one's pre-disaster home, but over the long run tended to increase the personal sense of recovery. In both the short-term and the longterm, living in one's own home tended to increase the sense of the village's recovery. On the other hand, being housed in publicly funded rental housing, which showed a low sense of recovery in 2013, in the long-run was not necessarily low as compared to living in one's predisaster home and it contributed more to a sense of the village's recovery in both 2013 and 2017. In addition, when a comparison was made of living in one's pre-disaster own home versus living in a home owned in a different location, it showed that the personal sense of recovery and that of the village tended to drop over the short-term, whereas it tended to increase for both over the long-term. It should be noted, however, it is possible that these results may have resulted from a change in the base case, which was the home in the same area.

In other words, if the impact of living in one's home in the disaster area lowered the sense of recovery over the long-term, this result may have been obtained even if the influence of other housing did not change much. In addition, regarding temporary housing, there was only one respondent in the 2017 survey, so we cannot judge the results for that year. In 2013, this accounted for more than $10 \%$ of the total, indicating that the sense of personal recovery tended to be low, while the sense of village recovery tended to increase.

\section{CONCLUSION}

This study has analyzed the factors affecting the sense of recovery of the victims of the Great East Japan Earthquake from both a short-term and a long-term perspective. We used the results of questionnaire surveys conducted in 2013 and 2017 of residents of Noda Village, Iwate Prefecture, to determine the factors that affected the sense of recovery of their personal lives as well as their sense of the recovery of the village itself. We also examined how differences in the choice of temporary housing affected their sense of recovery.

Decision tree analysis revealed that the severing of ties with workplace friends and changes in household size should be avoided. In order to do so, evacuations should to some extend be undertaken within a specific defined region. It was also shown that in the short term, it is important for their sense of recovery that victims maintain a personal network of immediate family members, other relatives and local workplace friends as well as assurances that their income would not diminish. However, in the long run, the sense of one's own recovery as well as that of the community in which one lives will be influenced by a number of other factors, and that a person's sense of his or her own recovery will be influenced by personal and economic factors such as changes in marriage circumstances and household income and savings that were brought on by the disaster. 
On the other hand, the sense of recovery of the village seems to have been influenced by family factors that included whether or not one was the firstborn, being able to consult with relatives as well as social status factors such as educational background. In this regard, for those whose relocation to another area proved to be difficult due their being the firstborn or their educational background, interest in the village tended to increase and it is possible that this was linked to their sense that the village was not recovering. In the short term, the sense of the recovery of the village seems to have been affected by changes in relationships with persons outside the village, the presence of children and the comparisons they make with other regions and exchanges within the region through their children. In the long run, factors that affect the sense of recovery will change, so it will be necessary to implement flexible policy and postdisaster management approaches.

As for temporary post-disaster housing, living in the same home as one did before the disaster increased the short-term sense of recovery, but it appears that this was not the case for the long-term. Although living in the home to which one is accustomed has the effect of helping that person rebuild his or her life in the short-term, due to the correlation between village-wide reconstruction plans and the location of one's home as well the differences in government subsidies, it is possible that in the long term it does not lead to a sense of recovery. Therefore, given the limited availability of temporary housing and publicly funded rental housing units, it will likely be necessary to have some or many of the disaster victims, depending upon the circumstances, live in their own home. However, from a long-term perspective, this may not be the best solution.

On the other hand, with regard to temporary housing, the sense of recovery was low in the short-term, but tended to increase over the long-term. Because the introduction of publicly funded rental housing deviated from the previous network of temporary housing, there is a possibility that the sense of rebuilding one's life will be reduced in the short-term. However, in the long-term, we think that the flexibility of movement has helped to raise the personal sense of recovery along with the sense of the recovery of the village itself.

According to Yamada (2020), the availability of publicly-funded temporary housing was $0.3 \%$ at the time of the 1995 Great Hanshin Awaji Earthquake, 56.6\% at the time of Great East Japan Earthquake in 2011 and 74.6\% at the time of 2016 Kumamoto Earthquake, which shows that the availability of this type of temporary housing increased year by year in Japan. However, as Yamada pointed out, in the short term, the degree of the satisfaction with life held by disaster victims dropped significantly, and the introduction of short-term support mechanisms, as taken up in this paper, and the correlation with how victims viewed their lives emerge as important issues that must be taken into consideration.

From the perspective of the effective utilization of unoccupied housing units and other housing resources as well as the prevention of the spread of infectious diseases like Covid-19, the promotion of the use of unoccupied housing banks to provide publicly-funded temporary facilities can offer up important policy options for future post-disaster countermeasures. In addition, as pointed out in our paper, the building of short-term support systems for publiclyfunded temporary housing is also a matter of urgency. 
There are some issues than remain regarding this study, the biggest of which is the sample size of the 2017 survey. For this survey, we included only the respondents who had answered all the items that were found in both the 2013 and 2017 surveys. As a result, the sample size of the 2017 survey was significantly reduced to 111 . Because the sample size was small, the responses were biased and an adequate analysis could not be carried out.

\section{REFERENCES}

Elliott, J. R., T. J. Haney, and Sams-Abiodum, P. (2010) Limits to Social Capital: Comparing Networks Assistance in Two New Orleans Neighborhoods Devastated by Hurricane Katrina, The Sociological Quarterly, 51(4): 624-648.

Eric C. J., and A. J. Faas. (2017) Social Network Analysis of Disaster Response, Recovery, and Adaptation. Butterworth-Heinemann

Haimes, Y.Y. (2012) System-Based Approach to Preparedness for, Response to, and Recovery from Natural and Human-Made Disaster, Leadership and Management in Engineering, 12(4): 288-298

Hawkins, R. L., and K. Maurer. (2010) Bonding, Bridging and Linking: How Social Capital Operated in New Orleans Following Hurricane Katrina, British Journal of Social Work, 40(6): 1777-1793.

Kim, K., and S. Yoon. (2018) Assessment of Building Damage Risk by Natural Disasters in South Korea Using Decision Tree Analysis, Sustainability, 10(4),

Kuromiya et al. (2006) 4 Recovery Patterns from the Hanshin-Awaji Earthquake: Using the 2001-2003-2005 Panel Data, Institute of Social Safety Science, 8: 1-10.

Kunitomo, N. (2013) Natural Disaster and Housing Problem: The Case of Higashi-NihonDaishisai, The Journal of Economics, 79(1): 2-16.

Landry et al. (2007) Going Home: Evacuation-migration Decisions of Hurricane Katrina Survivors, Southern Economic Journal, 74(2): 326-343.

Lee, Y., \& T. Atsumi. (2016) Higashi-nihon-daisinsai kara no fukkou (3) Tatsiagaru Noda: (Reconstruction after the Great East Japan Earthquake (3) Research for the Reconstruction Plan that considers QOL from the Great East Japan Earthquake) (in Japanese) Hirosaki University Press, p. 281.

Lee, Y., M. Nagata and T. Atsumi. (2014) Key Factors to Determine the Sense of Recovery from the Great East Japan Earthquake and Tsunami, Journal of Disaster Recovery and Revitalization, 6:1-8.

Lee et al. (2018) Nodamura shutshin no minasama no kurashi to oshigoto ni kansuru ankeito chōsa hōkokusho (Report of Questionnaire Survey on the Lives and Work of Graduates of 
Noda Junior High School) (in Japanese) Innovation Regional Research Center, Hirosaki University, p. 101.

Lee et al. (2013) Nodamura no minasama no kurashi to oshigoto ni kansuru ankeito chōsa hōkokusho (Report of Questionnaire Survey on the Lives and Work of Noda Villagers)(in Japanese) Faculty of Humanities and Social Sciences, Hirosaki University, p. 153.

Lee, Y., and H. Sugiura. (2014), Impact of the Great East Japan Earthquake on Intentions to Relocate, Journal of Integrated Disaster Risk Management, IDRiM (2014)4(2): 64-73.

Lee Y., H. Sugiura and I. Geciene. (2016), Stay or Relocate: The Roles of Networks after the Great East Japan Earthquake, Social Network Analysis of Disaster Response, Recovery, and Adaptation. Edited by Eric C. Jones and A.J. Faas, Butterworth-Heinemann, pp. 223238

Luu, C., J. Von Meding and S. Kanjanabootra. (2017) Analysing flood fatalities in Vietnam using national disaster database and tree-based methods, Natural Hazards and Earth System Science, discussions

Meyer, Michelle. (2017) The Family's Burden: Perceived Social Network Resources for Individual Disaster Assistance in Hazard-Prone Florida. Social Network Analysis of Disaster Response, Recovery, and Adaptation. Edited by Eric C. Jones and A.J. Faas, Butterworth-Heinemann, pp.127-142

Nagata, M. (2012) A 'Soft' Volunteerism in Super-Extensive Disaster: Case of Noda, East Japan Earthquake and Tsunami: Evacuation, Communication, Education and Volunteerism. Edited by Rajib Shaw and Yukiko Takeuchi., Research Publishing Services. Chap.12, pp.239-253.

Nagata, M. (2018) Shinsai nananenme no seikatsu-futkōkan (The sense of Recovery on the Seven years after 3.11 Tsunami)( in Japanese)Report of Questionnaire Survey on the Lives and Work of Graduates of Noda Junior High School. Edited by Lee et al, Innovation Regional Research Center, Hirosaki University, p. 101.

Paxson, C., and C. Rouse (2008) Returning to New Orleans after Hurricane Katrina, American Economic Review, 98(2): 38-42.

Thiede, B. C., and D. I. Brown (2013) Hurricane Katrina: Who Stayed and Why? Population Research and Policy Reviewer, 32(6): 803-824.

Yamada, T. (2020) Saigaiji ni okeru minashikasetsu jūtaku kyōyo no jittai to kadai (The current situation and issues of publicly funded temporary housing at the disaster)( in Japanese), Chihou Jichi Fukūka, 70:15-32. 